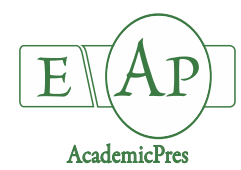

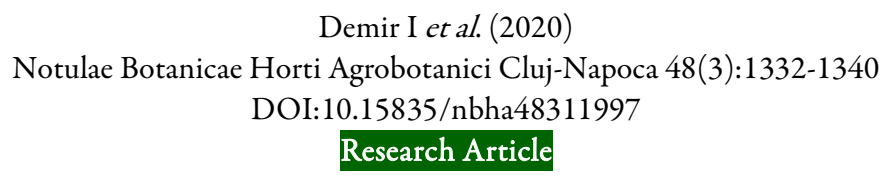

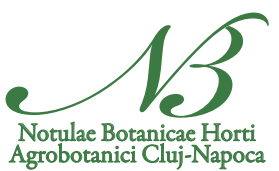

\title{
Molecular phylogeny based on its sequences of nrDNA of some species belonging to dodder (Cuscuta L.) genus from various ecological sites of Turkey
}

\author{
Ibrahim DEMIR ${ }^{1}$, Ilhan KAYA ${ }^{2 *}$, Mustafa USTA ${ }^{2}$, \\ Hikmet M. SIPAHIOĞLU ${ }^{3}$ \\ ${ }^{1}$ Bitlis Eren University, Faculty of Arts and Sciences, Department of Biology, Bitlis, Turkey; hosap65@gmail.com \\ ${ }^{2}$ Van Yuzuncu Yil University, Faculty of Agriculture, Department of Plant Protection, Van, \\ Turkey; ilhank@yyu.edu.tr (*correspondingauthor); mustafausta@yyu.edu.tr \\ ${ }^{3}$ Malatya Turgut Ozal University, Faculty of Agriculture, Department of Plant Protection, Malatya, Turkey; msipahi@hotmail.com
}

\begin{abstract}
Nuclear ribosomal DNA (nrDNA) sequence data of the Cuscuta genus, which have been considered as one of the most popular sequences for phylogenetic inference in plants, have been studied from a phylogenetic perspective in agricultural and non-agricultural lands of Turkey. The samples of Cuscuta spp. were collected from different geographical regions of Turkey between the years of 2013-2015. Some other species, not available locally, were taken from the herbarium samples of some research units. In order to study the phylogenetic relations of collected species, DNA isolations were made from body tissue samples. Conserved regions on ribosomal DNA (rDNA) were amplified by universal primers via PCR method and cloned into a proper cloning vector. The cloned DNA fragments were sequenced and analysed by web-based and computer programs. DNA sequences of certain species were recorded to the National Center for Biotechnology Information (NCBI) database. Based on the morphological examination and molecular analyses of fresh and the herbarium specimen, 8 species were identified. The identified species were $C$. hyalina (Gene bank accession no. KY020420), C. monogyna (KY020421), C. europaea (KY020422), C. palaestina (KY020423), C. approximata (KY020424), C. kurdica (KY020427), C. kotschyana (KY020430) and C. babylonica (KY020431). The ITS (Internal Transcribed Spacer) region contains several indels in identified Cuscuta species with the length varying from 668 to $730 \mathrm{bp}$. Sequence divergence ranges from 1.00\% to $8.00 \%$ within Cuscuta spp. Based on our findings, the ITS sequences provided phylogenetically informative results in combination with the secondary structures.
\end{abstract}

Keywords: classification; Cuscuta spp.; molecular phylogeny; Turkey

\section{Introduction}

Dodder (Cuscuta spp.) is evaluated as a flowering parasitic plant in the family of Convolvulaceae according to some researchers (Yuncker, 1932; Kujit, 1969; Parker and Riches, 1993; Linao et al., 2000). However, some others have been evaluating in the family of Cuscutaceae (Hadac and Chrtek, 1970; Davis, 
1978; Chertek and Obsornova, 1991). About 200 species are belonging to the genus Cuscuta and are commonly regarded as noxious weeds or invasive plants. Cuscuta is the third most harmful parasite plant group in the world after Striga and Orobanche (Parker and Riches, 1993; Costea and Tardif, 2006; Costea et al., 2006; Garcia et al., 2014). Dodder, Cuscuta species, is a parasitic annual plant that infests many agricultural crops such as alfalfa, clover, beans, soy, cranberry, some members of the grass family, trees, herbaceous plants, shrubs and various ornamentals in worldwide (Yunker, 1932; Li, 1987; Dawson et al., 1994; Maberley, 1997; Stefanovic and Olmstead, 2004). Members of the genus were recently implicated as vectors in the horizontal transfer of mitochondrial genes in plants (Mower et al., 2004).

Dodders are lack of vegetative organs such as root or leaf. The diagnosis of these plants can only be done by observation of flower and fruit characters. In general, difficulties are encountered in diagnosis made with taxonomic characters. Therefore, the identification of molecular phylogenetic relationships in the diagnosis of these plants provides a more reliable diagnosis (Nemli et al., 2015).

Cuscuta is an annual plant producing seeds that germinate on or near the soil surface. Germination is influenced by temperature, with an optimum at $30{ }^{\circ} \mathrm{C}$ (Benvenuti et al., 2005). Cuscuta spp. can produce 3.000-25.000 seeds. Most of the seeds remain dormant for 5-15 years, close to the soil surface (Hutchisan and Ashton, 1979).

Yuncker (1932) has been studied the Cuscuta through systematic studies about evolutionary relationships, character evolution, biogeography, and speciation. Stefanovic et al. (2007) has been defined as the major lineages of the subgenus Grammica, which is the largest and the most complicated infrageneric taxon of Cuscuta. Costea et al. (2008) have examined the phylogeny-based classification of the genus Cuscuta.

New methods of phylogenetic analysis have made it possible to clarify the early evolution of Magnoliophyta (Podoplelova and Ryzhakov, 2005). Until 1960, systematic information was obtained based on morphological and behavioral variations. After the 1960s, biological macromolecules have played an important role in evolutionary and systematic studies (Soltis et al., 1997).

PCR amplification of the ITS region on ribosomal DNA is now a popular option for phylogenetic analysis of closely related species and populations. This popularity has been enhanced by the production of universal primers that can bind to conserved rDNA regions. The data obtained as an analysis of ITS base sequences provide significant contributions to the solution of existing problems in the taxonomic categories. The relationships of the concerned taxa are usually determined by studying the ITS variations of the taxa. The major non-coding nuclear DNA region has been widely used for reconstruction, identification, and phylogenetic analysis of many plant families. ITS has been used in countless systematic studies at a wide variety of plant species and species levels (Baldwin et al., 1995).

Keskin et al. (2017) have been reported the analysis of nrDNA's ITS sequences as an efficient tool to study the phylogeny of dodders collected from various provinces of Eastern Anatolia (Turkey). The sequences of $18 \mathrm{~S}$ rRNA, ITS-1, 5.8S rRNA, ITS-2, and 26S rRNA regions of 4 Cuscuta species were determined by molecular cloning and sequencing. This study results clearly showed that the most stable secondary structure derived from the sequences obtained by universal ITS4 and ITS5 primers is a very efficient tool for the identification of Cuscuta species when used in combination with phylogenetic analysis.

Today, the universal primers are used for amplification and sequencing of the ITS region. Primers were originally designed for fungal rRNA amplification and are derived from fungal (Saccharomyces), insect (Drosophila), and plant (Oryza sativa and Hordeum vulgaris) sequences (White et al., 1990). Phylogenetic trees based on the sequence analysis results of ITS- 1 or ITS-2 regions may produce results not supported by other sequences. Therefore, the results of combining the information obtained from the ITS-1 and ITS-2 regions reveal more accurate, robust, and complete trees (Baldwin et al., 1995; Baldwin, 1992). This study aims to determine the phylogenetic relations of species belonging to the genus Cuscuta in Turkey. 


\section{Materials and Methods}

\section{Taxon sampling}

The plant materials of Cuscuta spp. were either field-collected from different geographical regions of Turkey or provided by herbarium samples of some universities between the years of 2013 and 2015 (Figure 1), as indicated in the Flora of Turkey (Davis, 1978). A list of the 8 species of Cuscutaincluded in the analysis with their voucher deposition data, gene bank accession numbers, sources, collection site, and the length of amplified sequences are provided in Table 1.

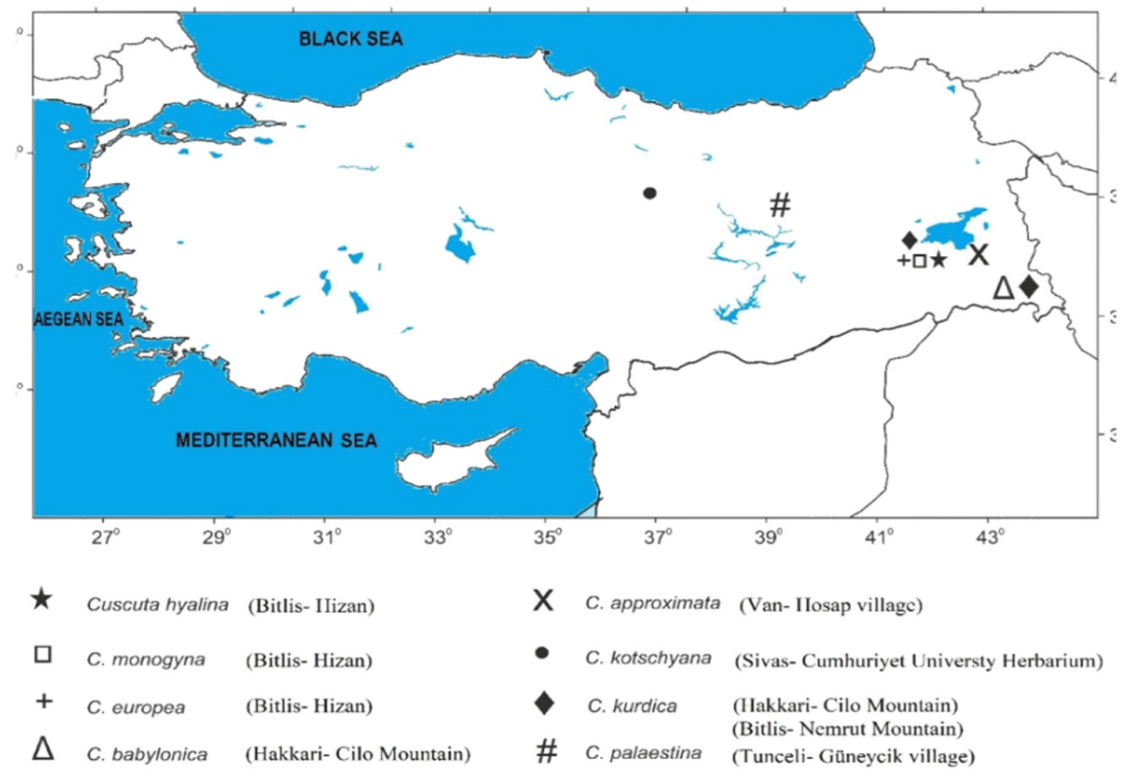

Figure 1. Locations and the species of Cuscuta spp. collected from different geographical regions of Turkey

Table 1. EMBL accession number and the source of sequences used

\begin{tabular}{|c|c|c|c|c|}
\hline Taxa & $\begin{array}{c}\text { No of Sample and } \\
\text { locality }\end{array}$ & $\begin{array}{c}\text { Gen Bank } \\
\text { accession number }\end{array}$ & Length (bp) & NCBI database \\
\hline Cuscuta hyalina & 1769 (Bitlis-Hizan) & KY020420 & 674 & HM748873.1 \\
\hline Cuscuta hyalina & Canada & HM748873 & 621 & \\
\hline Cuscuta hyalina & Turkey & KX683007 & 674 & \\
\hline Cuscuta monogyna & 1770 (Bitlis-Hizan) & KY020421 & 677 & AY554405.1 \\
\hline Cuscuta monogyna & $\mathrm{UK}$ & AY554405 & 737 & \\
\hline Cuscuta monogyna & China & KY456203 & & \\
\hline Cuscuta monogyna & Spain & DQ924569 & 606 & \\
\hline Cuscuta monogyna & Armenia & MH109269 & 636 & \\
\hline Cuscuta kotschyana & $\begin{array}{c}1817 \text { (Cumhuriyet } \\
\text { Univ. Her.) }\end{array}$ & KY020430 & 682 & DQ924587.1 \\
\hline Cuscuta kotschyana & Iran & DQ924585 & 610 & \\
\hline Cuscuta kotschyana & & DQ924587 & 611 & \\
\hline Cuscuta europaea & 1785 (Bitlis-Hizan) & KY020422 & 730 & AY554401.1 \\
\hline Cuscuta europaea & $\mathrm{UK}$ & AY554401 & 739 & \\
\hline Cuscuta palaestina & $\begin{array}{c}1792 \text { (Tunceli } \\
\text { Güneycik) }\end{array}$ & KY020423 & 682 & AY554406.1 \\
\hline Cuscuta palaestina & UK & AY554406 & 721 & \\
\hline Cuscuta approximata & 1808 (Van-Hoşap) & & & \\
\hline
\end{tabular}


Demir I et al. (2020). Not Bot Horti Agrobo 48(3):1332-1340

\begin{tabular}{|c|c|c|c|c|}
\hline Cuscuta approximata & 1809 (Van-Hoşap) & KY020424 & 682 & KU725873.1 \\
\hline Cuscuta epithymum & $\begin{array}{c}1810 \text { (İzmir- } \\
\text { Kemalpaşa) }\end{array}$ & KY020425 & 682 & KU725873.1 \\
\hline Cuscuta kurdica & $\begin{array}{c}1811 \text { (Bitlis-Nemrut } \\
\text { Mountain) }\end{array}$ & KY020426 & 685 & KU725873.1 \\
\hline Cuscuta kurdica & $\begin{array}{c}1811 \text { (Hakkari-Cilo } \\
\text { Mountain) }\end{array}$ & KY020427 & 678 & DQ924613.1 \\
\hline Cuscuta kurdica & Turkey & KY020428 & 679 & DQ924613.1 \\
\hline Cuscuta babylonica & $\begin{array}{c}1819 \text { (Hakkari-Cilo } \\
\text { Mountain) }\end{array}$ & DQ924613 & 607 & DQ924578.1 \\
\hline Cuscuta babylonica & Turkey & KY020431 & 611 & 696 \\
\hline Cuscuta babylonica & Afganistan & DQ924579 & 596 & \\
\hline Cuscuta babylonica & & DQ924578 & & \\
\hline
\end{tabular}

\section{DNA isolation and PCR: amplification}

Genomic DNA was extracted either from fresh Cuscuta spp.

Plants collected from the fields or attempted using dried material from herbarium specimens using a commercial DNA preparation kit (Thermo Scientific, USA). Species identification of collected plant samples was conducted basically on molecular (sequence analysis and secondary structure pattern of nrDNA) and morphological (flower structure) analyses.

The major non-coding nuclear DNA region (ITS1, 5.8S, and ITS2) were amplified by polymerase chain reaction (PCR) with universal oligonucleotide primers (ITS4-5'-TCCTCCGCTTATTGATATGC-3' and ITS5-5'-GGAAGTAAAAGTCGTAACAAGG-3') of White et al. (1990). The amplification of the ITS1/5.8S/ITS2 region was performed by polymerase chain reaction (PCR) in a final volume of $50 \mu \mathrm{l}$. The PCR mixture contained: $2 \mu \mathrm{l}$ of genomic DNA, $5 \mu \mathrm{l}$ of $10 \times$ reaction buffer $(200 \mathrm{mMTris}-\mathrm{HCl} \mathrm{pH}: 8.4,500$ $\mathrm{mMKCl}), 3 \mu \mathrm{l}$ of $\mathrm{MgCl} 2(25 \mathrm{mM}), 1 \mu \mathrm{l}$ of dNTPs (10 mM each), $1 \mu \mathrm{l}$ of each primer (100 pmol), $0.4 \mu \mathrm{l}$ of DNA polymerase, and $36.6 \mu \mathrm{l}$ of DNase free sterile water. The thermal regime of PCR reaction was set according to White et al. (1990). PCR products were separated and detected in a 1.5\% agarose gel as described by Sambrook (1989). The DNA fragments were isolated from the gel using Isolate II PCR and Gel Kit (Bioline, Germany). Purified DNA fragments were cloned and sequenced in both directions using two universal (SP6 and T7) primers by Iontek Company (Turkey). The accession numbers of the sequences studied in this paper have been given in Table 1 and deposited in the GenBank database.

\section{Molecular cloning and sequencing}

A total of 8 ITS sequences including ITS1/5.8S/ITS2 regions were molecularly cloned and sequenced. The upstream sense primer ITS4 and the downstream antisense primer ITS5 generated approximately 600700 bp DNA fragments. The PCR products were cloned by the TA cloning vector into the middle of two EcoRI sites of the pGEM T easy vector (Promega, USA) by following manufacturer's instructions to generate ITS1/5.8S/ITS2 region. To transform recombinant plasmids, the JM 109 strain of Escherichia coli was used as competent cells. Recombinant plasmids were screened by blue/white colour screening on X-gal containing plates and isolated from individual white colonies by a commercial plasmid purification kit (Thermo Fisher, USA). To check the success of the molecular cloning the DNA inserts were excised by digestion with EcoRI and electrophoresed on a $1.5 \%$ agarose gel.

\section{Predicting the most stable secondary structure}

All possible the most stable secondary structures of ITS1/5.8S/ITS2 regions for a total of 8 species sequences were modelled using the mfold structure prediction package of CLC RNA Workbench Version 6.2 (CLC bio, Denmark). Calculating free energies of all possible secondary structures and retaining one of the 
lowest energies (i.e., the most stable) is the basis of predicting thermodynamically the most stable rRNA molecule (Chastain and Tinoco, 1991).

\section{Phylogenetic analysis}

The phylogenetic analysis was performed on the ITS1/5.8S/ITS2 sequence of each species. The aligned sequences were visually inspected for possible mutations and gaps. Cladistics analyses and the relationships were performed with a computer program (CLC Main Workbench) under both parsimony and maximum likelihood criteria using 1000 bootstrap replicates. The phylogenetic tree was constructed with the CLC Main Workbench program by the Neighbour-Joining method.

\section{Results}

A total of 8 species out of 11 samples from various ecological sites of Turkey were molecularly studied for the systematic utility of nuclear ribosomal DNA sequences by assessing phylogenetic relationships in genus Cuscuta (Cuscutaceae). Complete ITS nucleotide sequences (including ITS1, ITS2, and the 5.8S rRNA gene) and partial sequences of $18 \mathrm{~S}$ and $26 \mathrm{~S}$ ribosomal RNA gene were determined by molecular cloning.

The average length of the sequenced ITS region of studied Cuscuta species was approximately $665 \mathrm{bp}$, as seen in Table 1. In pairwise comparisons of aligned complete ITS1 and ITS2 nucleotide sequences, species of Cuscuta were similar in $92-99 \%$ of each other. The species names, EMBL accession numbers, DNA length of all 8 taxa used in this study are given in Table 1. Overall, 59 variable nucleotides were observed among the sequenced species. The highest divergence was observed on $C$. hyalina in a group with twenty-three indels (deletions or insertions). The alignment of the 8 taxa indicated that $C$. babylonica was the next divergence species with eighteen indels. Seventeen variable characters were observed between $C$. babylonica and $C$. kotschyana sequences as indels clustered at the same clade.

All possible predicted secondary structures of ITS regions were modelled for 8 species of Cuscuta (Figure 2). The utility of secondary structure's topology has been evaluated to resolve phylogenetic relationships at the species level. C. monogyna contained the most frequent hairpin structures on its ITS sequence having 13 hairpin secondary structures among the 8 species analysed. The remaining species have mostly consisted of a minimum 8 and maximum 11 hairpin structures (Figure 2). Our study clearly showed that the same species consistently form similar topology in secondary structure models (Figure 2 panel $\mathrm{f}$ and $\mathrm{g}$ ).

To determine the degree of relationships and diversity between Cuscuta species phylogenetic analyses were performed. The resulting phylogenetic tree of ITS1 and ITS2 sequences gave a robust tree providing a strong resolution (Figure 3). The neighbour-joining tree was preferred since the tree offered more information and a better resolution with 1000 bootstrap values. The method divided 8 taxa into three major clusters. $C$. kotschyana, C. babylonica, C. monogyna and C. hyalina were clustered in the central largest group. C. europaea and $C$. palaestina were placed in the same clade because of the high level of sequence similarity. 
Demir I et al. (2020). Not Bot Horti Agrobo 48(3):1332-1340
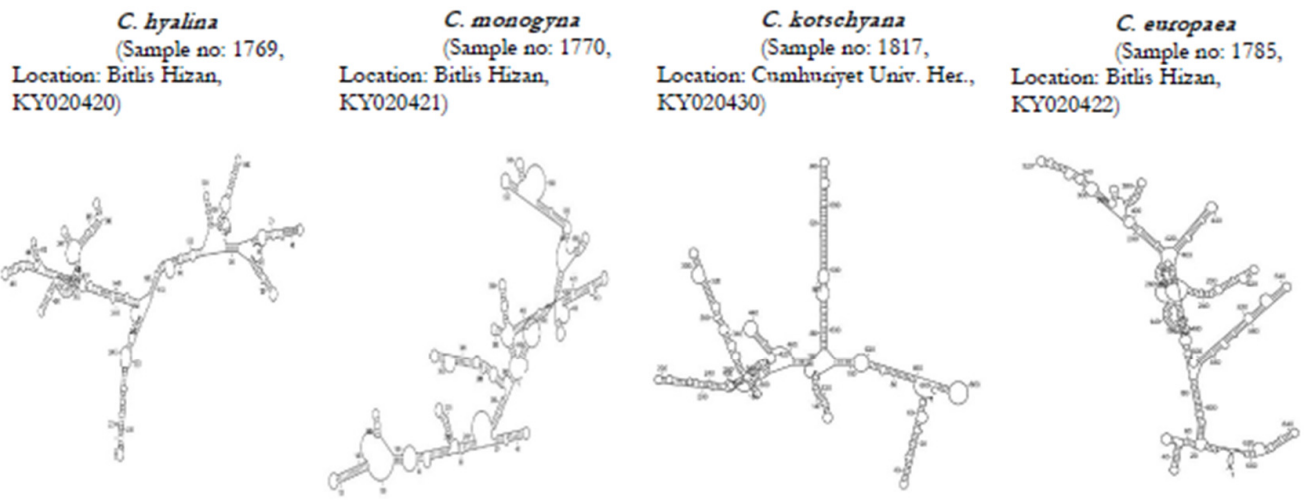

\section{C. kurdica (Sample no: 1811,} Location: Bitlis Nemmt Mountain, KY020427)
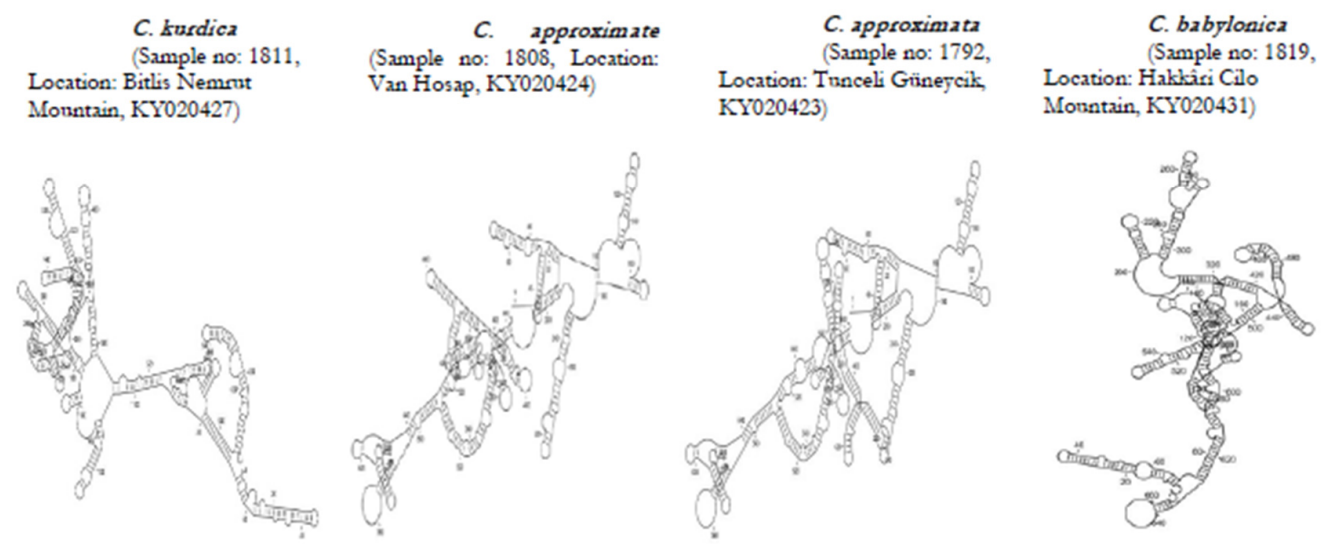

Figure 2. Secondary structures of ITS sequences of Cuscuta samples studied in this paper Note them multitudinous hairpin structures of C. monogyna. of C. hyalina (a), C. monogyna (b), C. kotschyana (c), C. europaea (d), C. kurdica (e), C. approximata (f), C. approximata (g) C. babylonica(h).

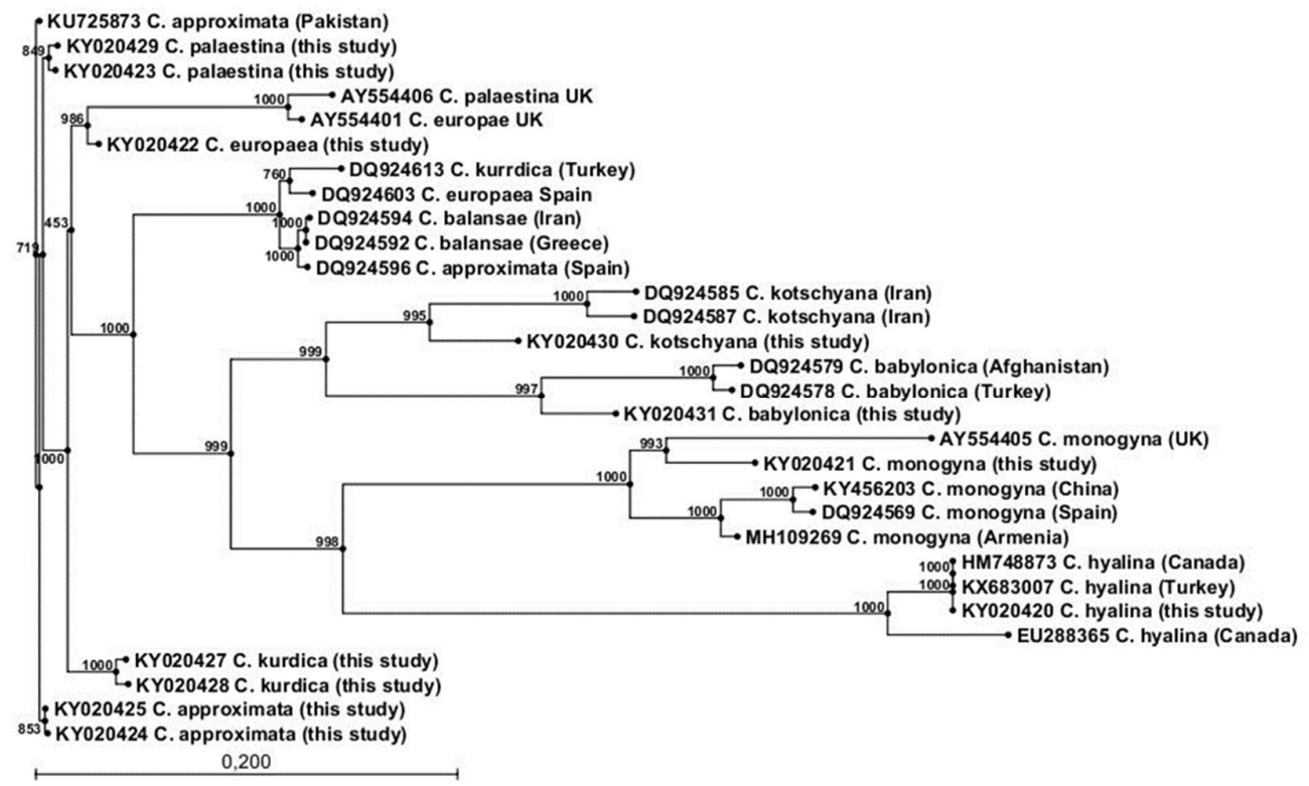

Figure 3. Phylogenetic analysis of the twelve ITS sequences observed among the species of $C$. hyalina, $C$. monogyna. C. europaea, C. palaestina, C. approximata, C. kurdica, C. kotschyana and C. babylonica Numbers on the branches represent the 1000 bootstrap replications in which a given branch appears 


\section{Discussion}

The molecular characteristics and the phylogenetic utility of ITS region of nuclear ribosomal DNA belonging to Cuscuta were analysed. ITS sequences were found suitable for phylogenetic comparisons at lower taxonomic levels. The present findings suggest that ITS sequences provide phylogenetically informative information and generate highly resolved trees with more strongly supported clades. To study phylogenetic relations among plant genera, the ITS sequences have been used widely in many weed and crop plants such as sorghum, maize, wheat, and cotton (Sonnate et al., 2003).

The entire ITS region (ITS1-5.8S-ITS2) has been generated successfully using the reported ITS4 and ITS5 primers and templates of the total cellular DNA of Cuscuta spp. as shown in Figure 2. The ITS region of nrDNA contains 59 indels in Cuscuta with the length varying from 688 to $730 \mathrm{bp}$. The traditional classification of Cuscuta species was consistent with the highly resolved phylogenetic tree constructed based on the ITS region. Based on ITS phylogeny, the 12 Cuscuta samples were differentiated into 8 main species.

The most stable secondary structure of ITS sequence of each defined species was constructed for all species studied in this research. Our study showed that the secondary structure of all studied species was exhibited diverse topology for each species which were enough to identify at the species level (Figure 2). It has been concluded that diverse species consistently form diverse topology in secondary structure models (Figure 2).

The combination of two molecular analyses (ITS sequencing and predicting the most stable secondary structure), was found successfully applicable in detecting and identifying dodders at the species level. Our results are in correlation with our previous study (Keskin et al., 2017) conducted with the Cuscuta species collected from different sites of East Anatolia (Turkey). In recent years, many studies have been combining the knowledge of the prediction of the most stable secondary structures of the nucleic acids and the phylogenetic analyses of ITS structures to provide a more comprehensive understanding of the molecular basis of the species studied (Nicholas et al., 2008).

Sequence analysis is very useful for phylogenetic analyses where morphological characters are inadequate (Yokoyama, 2000). Especially problems related to a diagnosis that cannot be resolved by taxonomic methods can be overcome by the evidence obtained from molecular data. One of the methods used for this purpose is ITS-PCR in the nrDNA region (Baldwin et al., 1995). Recent developments in molecular biology allow the identification of plant species by identifying species-specific gene regions. ITS-PCR is the most reliable method for phylogenetic studies to be carried out at the genus and species level. For this reason, ribosomal DNA internal transcribed spacers (rDNA ITS) are frequently used in parallel with the functioning of the plant systematics and genomic regions they have in definition (Baldwin et al., 1995).

\section{Conclusions}

Due to the reduced vegetative parts of parasitic plants, flower characters are generally used in the identification of Cuscuta species. Because sometimes these characters are also inadequate, for the diagnosis of Cuscuta L. genus, it is often necessary to combine molecular methods with morphological characters. Along with the evolutionary process, it is known that there are some variations between species and species in plants necessitating revision studies. In the present study, we determined that the secondary structure of the ITS sequences is highly conserved among the species in this study supporting successfully reconstructing the phylogenies at the species level. It has been concluded that the ITS sequences of nrDNA of Cuscuta provide enough data to identify and classify the economically relevant species along with the distinctive structural characters. 


\section{Authors' Contributions}

All authors read and approved the final manuscript.

\section{Acknowledgements}

This study was supported financially by the Scientific and Technological Research Council of Turkey (TÜBİTAK; project number: 113O418).

\section{Conflict of Interests}

The authors declare that there are no conflicts of interest related to this article.

\section{References}

Baldwin BG (1992). Phylogenetic utility of the internal transcribed spacers of nuclear ribosomal DNA in plants: an example from the Compositae. Molecular Phylogenetics and Evolution 1(1):3-16. https://doi.org/10.1016/1055-7903(92)90030-K

Baldwin BG, Sanderson MJ, Porter JM, Wojciechowoski MF, Campell CS, Donoghue MJ (1995). The ITS region of nuclear ribosomal DNA: Valuable source of evidence on angiosperm phylogeny. Annals of the Missouri Botanical Garden 2:250-272.

Benvenuti S, Dinelli G, Bonetti A, Catizone P (2005). Germination ecology, emergence and host detection in Cuscuta campestris. Weed Research 45:270-278. https://doi.org/10.1111/j.1365-3180.2005.00460.x

Chrtek J, Osbornova J (1991). Notes on the synanthropic plants of Egypt: 3. Grammica campestris and other species of family Cuscutaceae. Folia Geobotanica Phytotaxin 26:287-314. https://doi.org/10.1007/BF02912750

Costea M, Nesom GL, Stefanovic S (2006). Taxonomy of Cuscuta gronovii and Cuscuta umbrosa (Convolvulaceae). SIDA, Contributions to Botany 22:197-207.

Costea M, Tardif FJ (2006). The biology of Canadian weeds. Cuscuta campestris, C. gronovii, C. umbrosa, C. epithymum and C. epilinum. Canadian Journal of Plant Science 86:293-316. https://doi.org/10.4141/P04-077

Davis PH (1978). Flora of Turkey and the East Aegean Islands. Edinburgh University Press, Edinburgh.

Dawson JH, Musselman LJ, Wolswinkel P, Dorr I (1994). Biology and control of Cuscuta. Review of Weed Science 6:265317. https://doi.org/10.3732/ajb.1300449

García MA, Costea M, Kuzmina M, Stefanović S (2014). Phylogeny, character evolution, and biogeography of Cuscuta (dodders; Convolvulaceae) inferred from coding plastid and nuclear sequences. American Journal of Botany 101 (4):670-690. https://doi.org/10.3732/ajb.1300449

Hadac E, Chrtek J (1970). Notes on the taxonomy of Cuscutaceae. Folia Geobotanica Phytotaxin 5:443-445.

Hutchison JM, Ashton FM (1979). Effect of desiccation and scarification on the permeability and structure of the seed coat of Cuscuta campestris. American Journal of Botany 66:40-46. https://doi.org/10.1002/j.15372197.1979.tb06191.x

Keskin F, Kaya I, Usta M, Demir I, Sipahioglu HM, Nemli Y (2017). Molecular cloning and sequence analysis of the its region of nuclear ribosomal DNA for species identification in dodders (Cuscuta; Convolvulaceae). International Journal of Agriculture and Biology 19(6):1447-1451. https://doi.org/10.17957/IJAB/15.0442

Kujit J (1969). The biology of parasitic flowering plants. University of California Press, Berkeley.

Li YH (1987). Parasitism and integrated control of dodder on soybean, in parasitic flowering plants. Weber HC, Forstreuter W (Eds). Marburg, Germany, pp 497-500.

Liao GI, Chen MY, Kuoh CS (2000). Cuscuta L. (Convolvulaceae) in Taiwan. Taiwania 45:226-234.

Mabberley DJ (1997). The plant-book: A portable dictionary of the vascular plants. Cambridge University Press, Cambridge, UK. 
Mower JP, Stefanović S, Young GJ, Palmer JD (2004). Gene transfer from parasitic to host plants. Nature 432:165-166. https://doi.org/10.1038/432165b

Nemli Y, Kaya I, Tamer ŞR (2015). Cuscuta campestris. Turkey invasive plants catalog. Middle Black Sea Pass. Agricultural Research Station Directorate, Tokat.

Tippery NP, Les DH (2008). Phylogenetic analysis of the internal transcribed spacer (ITS) region in Menyanthaceae using predicted secondary structure. Molecular Phylogenetics and Evolution 49:526-537. https://doi.org/10.1016/j.ympev.2008.07.019

Parker C, Riches CR (1993). Parasitic weeds of the world. Biology and control. CAB International, Wallingford.

Podoplelova Y, Ryzhakov G (2005). Phylogenetic analysis of the order Nymphaeales based on the nucleotide sequences of the chloroplast ITS 2-4 region. Plant Science 169(3):606-611. https://doi.org/10.1016/j.plantsci.2005.05.006

Sambrook J, Fritsch EF, Maniatis T (1989). Molecular cloning: A laboratory manual, second edition, cold spring harbor laboratory press. Cold Spring Harbor, NY.

Soltis DE, Soltis PS, Nickrent DL, Johnson LA, Hahn WJ, Hoot SB, ... Sytsma KJ (1997). Angiosperm phylogeny inferred from $18 \mathrm{~S}$ ribosomal DNA sequences. Annals of the Missouri Botanical Garden 84:1-49. https://doi.org/10.2307/2399952

Sonnate G, Glasso I, Pignone D (2003). ITS sequence analysis and phylogenetic inference in the genus Lens Mill. Annals of Botany 91:49-54. https://doi.org/10.1093/aob/mcg007

Stefanović S, Olmstead RG (2004). Testing the phylogenetic position of a parasitic plant (Cuscuta, Convolvulaceae, Asteridae): Bayesian inference and the parametric bootstrap on data drawn from three genomes. Systematic Biology 53 (3):384-399. https://doi.org/10.1080/10635150490445896

Stefanović S, Kuzmina M, Costea M (2007). Delimitation of major lineages within Cuscuta subgenus Grammica(dodder; Convolvulaceae) using plastid and nuclear DNA sequences. American Journal of Botany 94:568-589.

White TJ, Bruns T, Lee S, Taylor JW (1990). Amplification and direct sequencing of fungal ribosomal RNA genes for phylogenetics. In: PCR protocols: A guide to methods and applications. (Innis MA, Gelfand DH, Sninsky JJ, White (Eds). Academic Press, New York, USA pp 315-322.

Yokoyama J, Suzuki M, Iwatsuki K, Hasebe M (2000). Molecular phylogeny of Coriaria, with special emphasis on the disjunct distribution. Molecular Phylogenetics and Evolution 14(1):11-19. https://doi.org/10.1006/mpev.1999.0672

Yunker TG (1932). The genus Cuscuta. Memoirs of the Torrey Botanical Club 18:113-331.

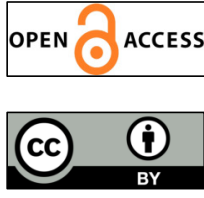

The journal offers free, immediate, and unrestricted access to peer-reviewed research and scholarly work. Users are allowed to read, download, copy, distribute, print, search, or link to the full texts of the articles, or use them for any other lawful purpose, without asking prior permission from the publisher or the author.

License - Articles published in Notulae Botanicae Horti Agrobotanici Cluj-Napoca are Open-Access, distributed under the terms and conditions of the Creative Commons Attribution (CC BY 4.0) License. (c) Articles by the authors; UASVM, Cluj-Napoca, Romania. The journal allows the author(s) to hold the copyright/to retain publishing rights without restriction. 